\title{
THE RATE OF SPERM PASSAGE INTO THE CERVIX AFTER COITUS IN THE RABBIT
}

\author{
J. M. BEDFORD \\ Department of Anatomy, and International Institute for the Study of Human \\ Reproduction, College of Physicians and Surgeons, Columbia University, \\ New York, U.S.A.
}

\section{(Received 29th June 1970)}

\begin{abstract}
Summary. Fluids instilled into the rabbit vagina are prevented from passing further along the tract by the valve-like disposition of the uterine cervix. In the present study, vaginal spermatozoa were killed at 2 or $5 \mathrm{~min}$ after coitus by instillation of 12 to $16 \mathrm{ml}$ of $1 \%$ lauryl sulphate (sodium dodecyl sulphate) into the anterior vagina. When the vaginal spermatozoa were killed 2 min after a single mating, only $25 \%$ of eggs were subsequently fertilized and there were essentially no accessory spermatozoa about the eggs. The fertilization rate was increased to $93 \%$, with a mean of 6.6 perivitelline spermatozoa/egg when killing of the vaginal spermatozoa was delayed until $5 \mathrm{~min}$ after a single mating. Thus, in the rabbit, sufficient numbers of vaginal spermatozoa for normal fertility enter the cervix within 5 min after coitus.

Early passage of spermatozoa into the cervix was much enhanced by a second successive coital stimulus, since destruction of all vaginal spermatozoa only $2 \mathrm{~min}$ after double mating allowed a $90 \%$ fertilization rate and a mean of 5.5 perivitelline spermatozoa/egg. Comparable results were achieved even if the second intromission was accomplished by a vasectomized male, pointing to the importance of the second coital stimulus rather than of the greater sperm numbers provided by double mating.
\end{abstract}

\section{INTRODUCTION}

The site of deposition of semen at coitus varies for different mammals. In the pig, horse, dog and murine rodents, whole semen (spermatozoa and seminal plasma) passes through the cervix into the uterine lumen at coitus. In women, cows, sheep and rabbits, on the other hand, semen is deposited only into the anterior vagina. To reach the uterus in these species, spermatozoa must then pass as individual cells into and through the mucus which fills the cervical lumen. The question "How do sperms get into the uterus?" was recently posed by Hartman in 1957, particularly in reference to this last group, and has been discussed by Walton (1960); however, the relative importance of sperm motility and the innate activity of the tract itself has still not been resolved. 
Another unknown factor investigated in the present study concerns the rate at which numbers of spermatozoa adequate for normal fertility enter the relative security of the cervical canal, i.e. for how long after ejaculation is the vaginal sperm pool of functional importance? In women, some spermatozoa often reach the internal os of the cervix within $1 \frac{1}{2}$ to 3 min after ejaculation (Sobrero \& MacLeod, 1962). In the cow, a few spermatozoa have been recovered from the ampullary region of the Fallopian tube within $3 \mathrm{~min}$ of ejaculation (VanDemark \& Hays, 1954) and within $8 \mathrm{~min}$ in the sheep (Starke, 1949; Mattner \& Braden, 1963). There is no indication, however, as to whether the numbers of spermatozoa in these sites could themselves maintain a normal fertilization rate. The present study was undertaken to determine the rate at which numbers of spermatozoa adequate for normal fertility pass from the vagina into the cervix after coitus in the rabbit.

\section{MATERIALS AND METHODS}

The experiments in this study involved destruction of all spermatozoa in the vagina by instillation of $1 \%$ lauryl sulphate (sodium dodecyl sulphate) at specified times after ejaculation at natural mating. This approach was employed on the assumption that instillation of 12 to $16 \mathrm{ml}$ of lauryl sulphate into the rabbit anterior vagina would immediately kill all vaginal spermatozoa, but not those which had reached the lumen of the cervix. This assumption was checked at laparotomy in fifty-three control females, after coitus and vaginal instillation of lauryl sulphate.

New Zealand White females were allowed to mate naturally; either one or two males from a standard group of ten New Zealand White bucks, known to be fertile, were used solely as stud males. Several groups, each consisting of ten females, were then subjected to different treatments, as follows: the females in Group 1 were mated once and those in Group 2 twice, with various stud males, and then were anaesthetized lightly with an intravenous injection of sodium pentobarbitone according to body weight; 50 i.u. of human chorionic gonadotrophin (HCG) were also given intravenously to ensure ovulation. The animals in these two control groups in which the vaginal spermatozoa were not destroyed were allowed to recover, but they were later killed by dislocation of the neck 20 to $23 \mathrm{hr}$ after mating; their ova were recovered and examined as described below.

The following treatments were applied in the experimental Groups 3 to 6 . Females in Group 3 were allowed to mate once; about $45 \mathrm{sec}$ after ejaculation, they were gently anaesthetized with sodium pentobarbitone. Lying supine, they then received 12 to $16 \mathrm{ml}$ of $1 \%$ lauryl sulphate into the anterior vagina from an insemination pipette, $2 \mathrm{~min}( \pm 10 \mathrm{sec})$ after ejaculation. An ovulating injection of 50 i.u. HCG was given intravenously, and a sample of fluid was removed from the anterior vagina both to check for the presence of spermatozoa and to ensure that all vaginal spermatozoa had been killed. The same procedure was repeated with the females in Group 4, except that with each of these the lauryl sulphate was instilled vaginally 5 min post coitum. The females in Group 5 were mated with two different males in rapid succession, the lauryl sulphate 


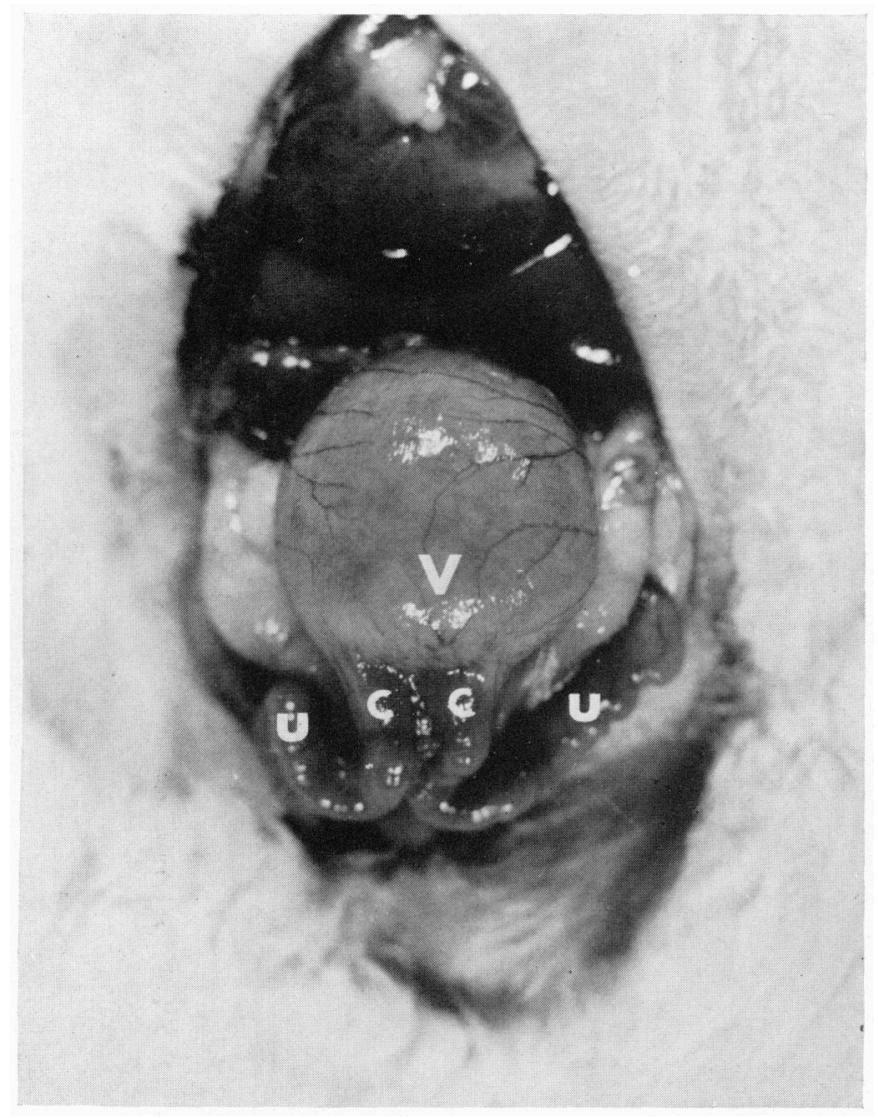

Vagina (V), cervices (C) and uterine horns (U) of a rabbit; exposed at laparotomy after vaginal instillation of $15 \mathrm{ml}$ lauryl sulphate. This fluid distends the vagina to some degree but does not enter the cervix or the uterus. 
being instilled $2 \mathrm{~min}( \pm 10 \mathrm{sec})$ after the first ejaculation. In Group 6, the second mating was performed by a vasectomized New Zealand White male, known to be azoospermic, but of normal libido.

In all cases, ova were recovered and examined as follows: the animals were killed by dislocation of the neck, and the Fallopian tubes were excised and were flushed with about $2 \mathrm{ml}$ of Ringer's solution. After mounting on slides, the eggs were examined in a phase contrast microscope; by rolling the eggs, the number of perivitelline spermatozoa could be counted with reasonable accuracy. After fixation in a mixture of glacial acetic acid and absolute alcohol in the proportions of $1: 3$, followed by staining with lacmoid, further examination was carried out to ascertain the numbers of eggs fertilized, as judged by the state of the second maturation spindle and by the presence of pronuclei and polar bodies, and a count was made of the total number of spermatozoa associated with each ovum.

The significance of the difference in the mean numbers of perivitelline and total spermatozoa about the eggs from different groups was derived by comparing various groups as matched pairs in the Student $t$ test.

\section{RESULTS}

The data from all experiments are presented in Table 1. In each animal in Groups 3 to 6, fluid recovered from the anterior vagina approximately $1 \mathrm{~min}$ after instillation of lauryl sulphate always contained spermatozoa; these were all dead and often tailless. This consistent finding, together with comparable observations at laparotomy in many control animals in which the anterior vagina was found to remain mildly distended by the detergent solution (Pl. 1),

TABLE 1

EFFECT ON FERTILIZATION OF DESTRUCTION OF VAGINAL SPERMATOZOA IN THE RABBIT AT VARIOUS TIMES AFTER MATING

\begin{tabular}{|c|c|c|c|c|c|c|c|}
\hline Group* & Experiment & $\begin{array}{l}\text { Total no. } \\
\text { of ova }\end{array}$ & Fertilization & $\begin{array}{c}\text { Perivitelline } \\
\text { sperm./ovum } \dagger\end{array}$ & S.D. & $\begin{array}{c}\text { Total } \\
\text { sperm./ovum } \dagger\end{array}$ & S.D. \\
\hline 1 & $\begin{array}{l}\text { Once mated } \\
\text { (control) } \\
\text { Untreated }\end{array}$ & 92 & 98 & $\begin{array}{l}13.4 \\
(2.5 \text { to } 40.0)\end{array}$ & $13 \cdot 2$ & $\begin{array}{l}30.20 \\
(10.0 \text { to } 75.0)\end{array}$ & $19 \cdot 1$ \\
\hline 2 & $\begin{array}{l}\text { Twice mated } \\
\text { (control) } \\
\text { Untreated }\end{array}$ & 106 & 100 & $\begin{array}{l}9 \cdot 0 \\
(2.5 \text { to } 15.0)\end{array}$ & 4.0 & $\begin{array}{l}25 \cdot 0 \\
(8 \cdot 5 \text { to } 43.0)\end{array}$ & $10 \cdot 7$ \\
\hline 3 & $\begin{array}{l}\text { Once mated } \\
\text { LS } 2 \text { min later }\end{array}$ & 121 & 25 & $\begin{array}{l}0.9 \\
(0 \text { to } 5 \cdot 0)\end{array}$ & $1 \cdot 8$ & $\begin{array}{l}1.6 \\
(0 \text { to } 8.5)\end{array}$ & $2 \cdot 6$ \\
\hline 4 & $\begin{array}{l}\text { Once mated } \\
\text { LS } 5 \text { min later }\end{array}$ & 90 & 93 & $\begin{array}{l}6 \cdot 6 \\
(0 \text { to } 21 \cdot 0)\end{array}$ & $7 \cdot 5$ & $\begin{array}{l}18 \cdot 8 \\
(0 \text { to } 47.0)\end{array}$ & $15 \cdot 1$ \\
\hline 5 & $\begin{array}{l}\text { Twice mated } \\
\text { LS } 2 \text { min later }\end{array}$ & 104 & 90 & $\begin{array}{l}5.5 \\
(0 \text { to } 10 \cdot 0)\end{array}$ & $3 \cdot 4$ & $\begin{array}{l}14 \cdot 8 \\
(0 \text { to } 45 \cdot 0)\end{array}$ & $12 \cdot 9$ \\
\hline 6 & $\begin{array}{l}\text { Once mated }+ \\
\text { vasectomized } \\
\text { LS } 2 \text { min later }\end{array}$ & 94 & 70 & $\begin{array}{l}5 \cdot 3 \\
(0 \text { to } 10 \cdot 0)\end{array}$ & $4 \cdot 1$ & $\begin{array}{l}15 \cdot 2 \\
(0 \text { to } 33.0)\end{array}$ & $12 \cdot 4$ \\
\hline
\end{tabular}

LS-Lauryl sulphate.

* Ten females per group.

$\dagger$ Average of the means from each animal with the range in parentheses. 
indicates that all the spermatozoa remaining in the vagina are killed promptly by the instillation of lauryl sulphate. By contrast, living spermatozoa were recovered in small numbers from the cervical canal in several of the control animals.

The untreated control Groups 1 and 2 consisted of females mated once and twice, respectively. As expected, the fertilization rate was very high $(98 \%$ to $100 \%$ ), and there were significant numbers of perivitelline and accessory spermatozoa. The slightly higher mean figure in Group 1 was caused by an abnormally large number of perivitelline spermatozoa (means of 33.0 and 40.0 ) in two females; however, the difference between the groups as a whole was not significant. The wide variation in mean numbers of perivitelline and accessory surface spermatozoa between different females was reflected in the range and large standard deviation for both parameters.

The fertilization rate was reduced to $25 \%$ in Group 3, in which all vaginal spermatozoa were killed 2 min after a single mating. Furthermore, there were very few perivitelline or accessory spermatozoa and six of the ten females in Group 3 had no spermatozoa associated with the ova recovered some $10 \mathrm{hr}$ after ovulation. It appears that significant numbers of spermatozoa must move from the vagina into the cervix between 2 and 5 min after a single mating, since an essentially normal fertilization rate $(93 \%)$ was maintained by the females in Group 4, in which all vaginal spermatozoa were killed only $5 \mathrm{~min}$ after a single mating. Perivitelline and accessory spermatozoa were present almost consistently (means of 6.6 and 18.8 , respectively), though, as in all other groups, great variation occurred in the mean number of spermatozoa around eggs from different individuals within the group. In Group 5, by contrast with Group 3, the imposition of a second mating immediately following the first allowed a maximal fertilization rate $(90 \%)$, even though all vaginal spermatozoa were destroyed only $2 \mathrm{~min}$ after the first ejaculation. This increased fertilization rate was also accompanied by an obvious significant increase $(P<0.01)$ in the number of spermatozoa associated with the recovered ova. In Group 6 in which the second intromission was achieved by a vasectomized male, the fertilization rate was only slightly lower $(70 \%)$; moreover, comparable sperm numbers were found within and around the recovered eggs, despite the fact that no extra spermatozoa were contributed by the second mating.

The same fertile males were used for each treatment group, but no clear or consistent association was apparent between sperm numbers on eggs and different males; the source of this variation in each group seems to have been attributable rather to the female.

\section{DISCUSSION}

Walton (1930) has drawn attention to the fact that the uterine cervix of the rabbit projects into the lumen of the anterior vagina; it has the disposition of a valve (cf. the ileo-caecal valve in man). Walton reasoned that this valve-like arrangement of the cervix would tend to promote closure of the cervical canal in response to fluid pressure in the vagina; he showed that dyes instilled into the anterior vagina bathe, but never pass beyond, the external os of the cervix. In 
the present study, control observations on many animals at laparotomy revealed that the bulk of lauryl sulphate was retained in, and mildly distended, the anterior vagina. Similar distension occurs not uncommonly at laparotomy by backflow of urine from the bladder.

The present experiments were performed mainly as an approach to the question of how long after coitus the vaginal sperm pool constitutes a reserve of importance for normal fertility. While the pattern of results in Table 1 indicates that functionally significant numbers of spermatozoa soon pass into the security of the cervical canal after coitus in the rabbit, the low fertilization rate and the extremely small number of perivitelline and accessory spermatozoa about the eggs make it clear that relatively few spermatozoa gain the cervical canal within 2 min after only one mating stimulus. Between 2 and 5 min after coitus, a very rapid build-up of sperm numbers clearly occurs within the cervix, since destruction of all vaginal spermatozoa only 5 min after a single mating (Group 4) resulted in a normal fertilization rate of $93 \%$. Furthermore, the supplementary spermatozoa in Group 4, though somewhat fewer than in the controls $(P<\sim 0.1)$, were present in some individuals in numbers comparable to those seen after normal mating. It is inferred, therefore, that the numbers of spermatozoa which enter the cervix in the first 5 min after a single mating are apparently more than sufficient to support a normal fertilization rate in most females. In the rabbit, the vaginal sperm pool seems not to be of importance for normal fertility for longer than $5 \mathrm{~min}$. These fertilization results lend credence to earlier observations by Parker (1931), who found some spermatozoa at, or just beyond, the internal os only 110 to $180 \mathrm{sec}$ after coitus; however, it is unlikely, as Parker suggests, that "a volume of spermatic fluid" enters the cervix and uterus.

There are differences in the physiology of coitus in rabbits and man, involving semen coagulation and depth and frequency of intromission. Nonetheless, the present results seem broadly comparable to those of Sobrero \& MacLeod (1962) who found motile spermatozoa at the internal os, sometimes in large numbers, only 90 to $180 \mathrm{sec}$ after ejaculation into the vagina in a high proportion of mid-cycle women. In this context, the present findings perhaps also serve to emphasize the uncertainty of the postcoital douche as a contraceptive technique.

The relative importance of the factors which determine the passage of spermatozoa through the cervix has not been determined, but it seems likely that the motility of the spermatozoa and the activity of the female tract both contribute to a degree which may vary with different situations. In the sheep, cow and woman, inert particles and dead spermatozoa may move from the vagina to the tubal ampulla (VanDemark \& Hays, 1954; Egli \& Newton, 1961; Mattner \& Braden, 1963), but sperm motility is necessary for effective colonization of the cervix (Mattner \& Braden, 1969). The present results indicate that a second coital stimulus closely following previous intromission and ejaculation much enhances the rate of passage of vaginal spermatozoa into the cervix. This somewhat unexpected effect of a sequential second mating is emphasized further by the large difference between Group 3, and either Group 5 or 6 in the numbers of perivitelline and accessory spermatozoa around the ova $(P<0.01$ for both parameters), and by the fact that the mean number of perivitelline 
sperm in the latter groups hardly differs from that in the twice-mated controls. That similar results were obtained regardless of whether the second male was intact or vasectomized, demonstrates the primary importance of the copulatory stimulus, or possibly of the seminal plasma, rather than of the additional sperm numbers. Although rabbit seminal plasma does not appear to contain pharmacologically or physiologically significant amounts of active prostaglandins which might act to heighten the contractile activity of the female tract (Eliasson, 1959), this line of thought cannot yet be ruled out. Similarly, a second intromission may have the effect of increasing the intensity and/or frequency of vaginal contractions. Rubenstein (1943) has speculated upon the possible importance of vaginal contractions during sperm entry into the human cervix, and Krehbiel \& Carstens (1939) have claimed that digital stimulation of the rabbit vulva facilitated passage of radio-opaque fluid through the cervix. The experiments of the latter authors were carried out under non-physiological conditions, however, in which conscious rabbits were strapped to flat boards. Furthermore, the conclusion of Krehbiel \& Garstens that whole semen normally passes the cervix to enter the rabbit uterus, does not agree with observations on the disposition of spermatozoa within the different regions of the tract soon after coitus (Braden, 1953).

In some species, the passage of spermatozoa in the female may be facilitated by oxytocin released at coitus, for this hormone has been detected in peripheral blood $1 \mathrm{~min}$ after orgasm in women (Fox \& Knaggs, 1969) and has been found in the blood of sheep after stimulation of the vulva (Roberts \& Share, 1968). It may be pertinent in the present context that in oestrogen-primed female rabbits, there is a critical dose of oxytocin ( $80 \mathrm{~m}$-unit) which, given intravenously, will bring about mass transport of spermatozoa through the cervix (Morton, 1969). Although it is questionable whether oxytocin is normally released at coitus in the rabbit (Sharma \& Chaudhury, 1970; Fuchs, A.-R., personal communication), the compound effect of a double mating might possibly provide a sufficient stimulus for its release.

By contrast with the above results, double mating did not ensure significantly greater numbers of perivitelline or total spermatozoa on the eggs from untreated control animals. Thus, while the stimulus of a second mating enhances the rate of early passage of vaginal spermatozoa into the cervix in the immediate postcoital period, it is apparent that neither the stimulus itself nor the extra spermatozoa contributed by a second intromission have any influence on the number of spermatozoa which penetrate or become attached to the egg. Indeed, when all vaginal spermatozoa were destroyed only $5 \mathrm{~min}$ after a single mating (Group 4), the mean number of perivitelline spermatozoa, though somewhat lower $(P<\sim 0 \cdot 1)$, nonetheless approached that of the untreated controls in Groups 1 and 2, there being no real difference in the respective fertilization rates. These data all emphasize the fact that once a sufficient number of spermatozoa is inseminated (in the rabbit, about $10 \times 10^{6}$ ), there is no clear positive relationship thereafter between the numbers of spermatozoa placed in the vagina and the number which penetrate or become attached to the egg, providing that the time between insemination and ovulation remains constant. Though not necessarily in accord with the early postulates of Walton 
(1938), this agrees with the experimental data of Chang (1951b, 1958) who found that the number of spermatozoa recovered from the rabbit oviduct was relatively constant, regardless of whether $200 \times 10^{6}$ or $20 \times 10^{6}$ spermatozoa were inseminated into the vagina. Likewise, Braden (1953) found that although females mated once or twice had only about one-third the numbers of uterine spermatozoa found in those mated six to ten times, there was no difference in the mean number of spermatozoa on their eggs.

It is not clear whether the interference involved in anaesthesia and handling had any effect on sperm transport in the control groups in this study. The mean numbers of perivitelline and total spermatozoa around the ova from females in Groups 1 and 2 were lower than those reported by Braden, Austin \& David (1954), but they fell within the same range as those found by others (Moricard \& Bossu, 1949; Chang, 1951a). The figures for these indices quoted by Adams (1956) are lower, but it should be noted that his investigation involved the interference of laparotomy and unilateral tubal ligation; furthermore, the figures were taken from eggs produced by superovulation, which itself might well bring about a dilution of the competent tubal spermatozoa available to each egg.

\section{ACKNOWLEDGMENTS}

I wish to express my thanks to Mary-Jane Bent for her help. This study was supported by NIH grant HD-03623.

\section{REFERENCES}

ADAMs, C. E. (1956) The frequency of occurrence of supernumerary spermatozoa in rabbit ova. Stud. Fert. 7, 130.

Braden, A. W. H. (1953) Distribution of sperms in the genital tract of the female rabbit after coitus. Aust. 7. biol. Sci, 6, 693.

Braden, A. W. H., Austin, C. R. \& David, H. A. (1954) The reaction of the zona pellucida to sperm penetration. Aust. F. biol. Sci. 7, 391.

Chang, M. C. (1951a) Fertility and sterility as revealed in the study of fertilization and development of rabbit eggs. Fert. Steril. 2, 205.

Chang, M. C. (1951b) Fertilization in relation to the number of spermatozoa in the fallopian tubes of rabbits. Annali Ostet. Ginec. 73, 918.

Chang, M. C. (1958) Fertilizing capacity of spermatozoa. In: Endocrinology of Reproduction, p. 131. Ed. C. W. Lloyd. Academic Press, New York.

Eoli, G. E. \& Newton, M. (1961) The transport of carbon particles in the human female reproductive tract. Fert. Steril. 12, 151.

Eliasson, R. (1959) Studies on prostaglandin (occurrence, formation and biological actions). Acta physiol. scand. 46, Suppl. 158, 1.

Fox, C. A. \& KNAGGs, G. S. (1969) Milk ejection activity (oxytocin) in peripheral venous blood in man during lactation and in association with coitus. F. Endocr. 45, 145.

Hartman, G. G. (1957) How do sperms get into the uterus? Fert. Steril. 8, 403.

KREhbiel, R. H. \& Carstens, H. P. (1939) Roentgen studies of the mechanism involved in sperm transportation. Am. J. Physiol. 125, 571.

MAtTneR, P. E. \& Braden, A. W. H. (1963) Spermatozoa in the genital tract of the ewe. I. Rapidity of transport. Aust. F. biol. Sci. 16, 473.

Mattner, P. E. \& Braden, A. W. H. (1969) Comparison of the distribution of motile and immotile spermatozoa in the ovine cervix. Aust. F. biol. Sci. 22, 1069.

Moricard, R. \& Bossu, J. (1949) Numération des spermatozoïdes au voisinage de l'ovocyte de lapine. Bull. Ass. Gynéc. Obstét. Lang. fr. 1, 30.

Morton, D. B. (1969) Influence of oxytocin on transport of spermatozoa in ovariectomized female rabbits. F. Endocr. 45, vi. (Abstr.). 
PARKer, G. H. (1931) The passage of sperms and eggs through the oviducts in terrestrial vertebrates. Phil. Trans. R. Soc. B, 219, 381.

Roberts, J. S. \& Share, L. (1968) Oxytocin in plasma of pregnant, lactating and cycling ewes during vaginal stimulation. Endocrinology, 83, 272.

RuBenstein, B. B. (1943) The transportation and survival of sperm in the vaginal and cervical canals. In: Problems of Human Fertility, p. 101. Ed. E. T. Engle. George Banta, Menasha, Wis.

Sharma, S. C. \& Chaudhury, R. R. (1970) Studies on mating. Part I. The absence of release of oxytocin at mating in female rabbits. Ind. 7. med. Res. 58, 495.

Sobrero, A. J. \& MacLeod, J. (1962) The immediate postcoital test. Fert. Steril. 13, 184.

StaRke, N. C. (1949) The sperm picture of rams of different breeds as an indication of their fertility. II. The rate of sperm travel in the genital tract of the ewe. Onderstepoort 7. vet. Sci. Anim. Ind. 22, 415.

VanDemark, N. L. \& Hays, R. L. (1954) Rapid sperm transport in the cow. Fert. Steril. 5, 131.

Walton, A. (1930) On the function of the rabbit cervix during coitus. 7. Obstet. Gynec. Br. Emp. $37,92$.

Walton, A. (1938) The quantitative basis of fertility. Folia morph. 8, 270.

Walton, A. (1960) Copulation and natural insemination. In: Marshall's Physiology of Reproduction, Vol. I, Part 2, p. 152. Ed. A. S. Parkes. Longmans, London. 